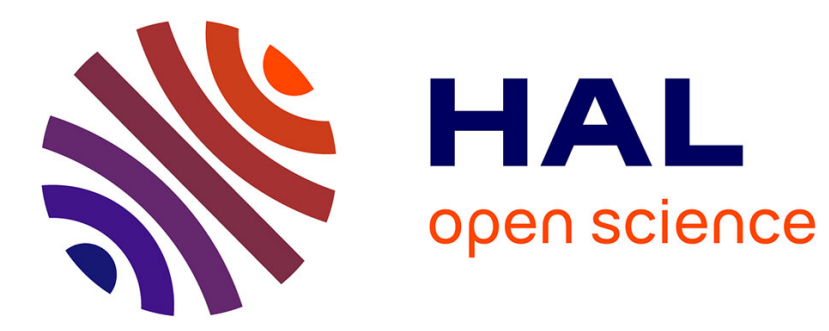

\title{
Necessary versus equal players in axiomatic studies
}

Sylvain Béal, Florian Navarro

\section{To cite this version:}

Sylvain Béal, Florian Navarro. Necessary versus equal players in axiomatic studies. Operations Research Letters, 2020, 48 (3), pp.385-391. 10.1016/j.orl.2020.04.011 . hal-03252179

\section{HAL Id: hal-03252179 \\ https://univ-angers.hal.science/hal-03252179}

Submitted on 7 Jun 2021

HAL is a multi-disciplinary open access archive for the deposit and dissemination of scientific research documents, whether they are published or not. The documents may come from teaching and research institutions in France or abroad, or from public or private research centers.
L'archive ouverte pluridisciplinaire HAL, est destinée au dépôt et à la diffusion de documents scientifiques de niveau recherche, publiés ou non, émanant des établissements d'enseignement et de recherche français ou étrangers, des laboratoires publics ou privés. 


\title{
NECESSARY VERSUS EQUAL PLAYERS IN AXIOMATIC STUDIES
}

\author{
Sylvain Béal ${ }^{\mathrm{a}}$, Florian Navarro ${ }^{\mathrm{b}, *}$ \\ ${ }^{a}$ CRESE EA3190, Univ. Bourgogne Franche-Comté, F-25000 Besançon, France. \\ ${ }^{b}$ GRANEM, Université d'Angers, 13 allée François Mitterrand, 49036 Angers, France
}

\begin{abstract}
This note introduces three variants of existing axioms in which equal players are replaced by necessary players. We highlight that necessary players can replace equal players in many wellknown axiomatic characterizations, but not in all. In addition, we provide new characterizations of the Shapley value, the class of positively weighted Shapley values, the Solidarity value and the Equal Division value. This sheds a new light on the real role of equal treatment of equals in the axiomatic literature.
\end{abstract}

Keywords: Necessary players, equal players, equal treatment of necessary players, (weighted-)Shapley value, Equal Division value, Solidarity value.

\section{Introduction}

The axiom of equal treatment of equals is essential in axiomatic studies and in particular in cooperative game theory where it imposes that two players with the same marginal contributions to coalitions obtain the same payoff. The most well-known sharing rules for cooperative games, such as the Shapley value [23], the Solidarity value [21], the Equal Division value and the Equal Surplus Division value all satisfy this axiom. Such values are often characterized by equal treatment of equals together with extra axioms.

In recent years, several works have tried to eliminate the unnecessary requirements in axiomatic studies in order to pinpoint the minimal associations of axioms that can characterize a sharing rule. Not surprisingly, this recent literature has been very active with regard to the Shapley value. [4] introduces a differential version of the axiom of marginality [31], [29] and [30] weaken the axiom of balanced contributions [19], [5, 6] weakens equal treatment of equals by requiring only identical signs for the payoffs of equal players or mutually dependent players, among others. To sum up, there are perhaps two ways to weaken the axiom of equal treatment of equals: weakening the requirement of the axiom by imposing equal signs instead of equal payoffs and restricting the set of players to which this requirement applies by considering only certain equal players but not all.

The present note is in line with this recent literature: we focus on the second approach, even if we sometimes combine both. Instead of equal players, we only consider necessary players, also called veto players in simple games [see for instance 25]. A player is necessary if each coalition

\footnotetext{
${ }^{*}$ Corresponding author. We thank an associated editor, an anonymous reviewer and Philippe Solal for fruitful suggestions.

Email addresses: sylvain.beal@univ-fcomte.fr. (Sylvain Béal), floriannavarro.unipro@gmail.com (Florian Navarro) 
without this player has a null worth. The first axiom involving necessary players comes from [28] in the context of games with a permission structure. The veto equal loss property invoked in [27] is, to the best of our knowledge, the sole axiom in classical cooperative games involving necessary players so far. Necessary players also emerge naturally in some applications. As an example, [9] study sequential liability games in which each member of the group of initial tortfeasors is a necessary player. Other such applications, in particular in operations research, are listed in [1] and emphasize the importance of analyzing necessary players from a theoretical point of view.

In this note, we offer a complete comparison between necessary and equal players, which in particular clarifies the exact role of equal treatment of equals in the axiomatic literature. This study relies on the introduction of new axioms involving necessary players. Our results answer the following three questions.

1. Do the characterizations in which equal players are treated equally persist when only necessary players are treated equally?

2. Do the characterizations in which the payoffs of equal players must have the same sign persist when it is only required that the payoffs of necessary players have the same sign?

3. Do the characterizations in which an axiom dealing with equal coalitions (instead of equal players) persist when only necessary coalitions are considered?

In order to answer question 1, we introduce the axiom of equal treatment of necessary players and prove that this axiom is weaker than the axiom of equal treatment of equals, even in presence of natural extra axioms such as efficiency, linearity, monotonicity [15] and coalitional monotonicity. This highlights that equal treatment of necessary players cannot replace equal treatment of equals in the characterization of the large family of sharing rules satisfying linearity, efficiency and equal treatment of equals by [22] and in the characterization of the family of procedural values by [16]. We also prove that any sharing rule satisfying equal treatment of necessary players together with linearity and self-duality also satisfies equal treatment of equals. We also highlight that equal treatment of necessary players can replace equal treatment of equals in the characterizations of the Shapley value by [24] and [31], of the Equal Division value in [26] and of the Solidarity value in [21], among others. The proofs of several of these results are immediate while others need some adaptation. The axiom of equal treatment of necessary players has already been studied recently by [20] for cooperative games enriched by a communication graph, who shows that this axiom is at the origin of the fairness axiom satisfied by the Myerson value [18]. It has also been used by [17] to offer a characterization of the Myerson value, the between groups Myerson value and the within groups Myerson value [11].

In order to answer question 2, we introduce the axiom of equal sign for necessary players, which imposes that the payoffs of two necessary players have the same sign. This axiom is weaker than the axioms of sign symmetry (identical signs for the payoffs of equal players) and weak sign symmetry (identical signs for the payoffs of mutually dependent players) introduced in $[5,6]$. We prove that the characterization of the class of positively weighted Shapley values in [6] is still valid when weak sign symmetry is replaced by equal sign for necessary players.

The answer of question 3 relies on two coalitional variants of equal treatment of necessary players that are similar to those studied in [3]. In that article, equal coalitions are considered instead of equal players and two axioms are introduced: one requiring the same total payoff for two equal coalitions, one requiring the same average payoff within two equal coalitions. We propose two similar axioms in which necessary coalitions replace equal coalitions: equal treatment of necessary coalitions and average equal treatment of necessary coalitions. We confirm two results in [3] 
by showing that there is no sharing rule satisfying equal treatment of necessary coalitions and efficiency while the Equal Division value is the unique sharing rule that satisfies efficiency, linearity and average equal treatment of necessary coalitions.

The rest of the note is organized as follows. Section 2 provide definitions. Section 3 introduces the axiom of equal treatment of necessary players and compares it with equal treatment of equals, in particular by revisiting existing characterizations of the Shapley value, Solidarity value and Equal Division value. Section 4 introduces the axiom of equal sign for necessary players and provides a characterization of the positively weighted Shapley values. Section 5 introduces the two coalitional variants of equal treatment of necessary players and presents an impossibility result as well as a characterization of the Equal Division value. Section 6 concludes with some remarks.

\section{Preliminaries}

Throughout this note, we fix a finite player set $N=\{1, \ldots, n\}$ with $n \geq 2$. Any subset $S$ of $N$ is called a coalition and its cardinality is denoted by $s$. A coalitional game with transferable utility (simply game henceforth) on $N$ is a characteristic function $v: 2^{N} \rightarrow \mathbb{R}$ such that $v(\emptyset)=0$. Let $\Gamma$ be the set of all those games on $N$. We call unanimity game induced by $R$ the game $u_{R}$ with $u_{R}(S)=1$ if $R \subseteq S$ and $u_{R}(S)=0$ otherwise. It is well-known that the set of unanimity games is a basis for the set of games $\Gamma$. More specifically, for each $v \in \Gamma$ :

$$
v=\sum_{S \subseteq N: S \neq \emptyset} \Delta_{v}(S) u_{S}
$$

where $\Delta_{v}(S)$ is called the Harsanyi dividend of coalition $S$ and can be defined recursively by setting $\Delta_{v}(S)=v(S)-\sum_{T \subsetneq S, T \neq \emptyset} \Delta_{v}(T)$. The Dirac game induced by $R$ is the game $\delta_{R}$ with $\delta_{R}(S)=1$ if $R=S$ and $\delta_{R}(S)=0$ otherwise. The set of Dirac game is obviously another basis for the set of games $\Gamma$ since

$$
v=\sum_{S \subseteq N: S \neq \emptyset} v(S) \delta_{S}
$$

Two players $i, j \in N$ are equal in the game $v$ if $v(S \cup\{i\})=v(S \cup\{j\})$ for each $S \subseteq N \backslash\{i, j\}$. A player $i \in N$ is necessary in game $v$ if $v(S)=0$ for each $S \subseteq N \backslash\{i\}$. A player $i \in N$ is null in game $v$ if $v(S \cup\{i\})=v(S)$ for each $S \subseteq N \backslash\{i\}$. A player $i \in N$ is nullifying in game $v$ if $v(S \cup\{i\})=0$ for each $S \subseteq N \backslash\{i\}$. Two players $i, j \in N$ are mutually dependent in a game $v$ if, for each $S \subseteq N \backslash\{i, j\}, v(S \cup\{i\})=v(S)=v(S \cup\{j\})$. A coalition $S$ is necessary if $v(T)=0$ for each $T \subseteq N \backslash S$. The average marginal contribution of the players in coalition $S$ is denoted by $A^{v}(S)=\sum_{k \in S}[v(S)-v(S \backslash\{k\})] / s$. A player $i \in N$ is $A$-null in game $v$ if $A^{v}(S)=0$ for each $S \subseteq N$ such that $i \in S$.

A permutation $\pi$ on $N$ assigns a position $\pi(i) \in\{1, \ldots, n\}$ to each player $i \in N$. The coalition containing player $i$ and the set of its predecessors in $\pi$ is denoted by $P_{i}^{\pi}=\{j \in N: \pi(j) \leq \pi(i)\}$. Let $\Pi$ be the set of $n$ ! permutations on $N$. Given $v \in \Gamma$ and $\pi \in \Pi, \pi v \in \Gamma$ is defined as: for each nonempty $S \subseteq N, \pi v\left(\cup_{i \in S} \pi(i)\right)=v(S)$. For each games $v, w \in \Gamma$ and $\alpha \in \mathbb{R}$, the game $(v+\alpha w) \in \Gamma$ is such that, for each $S \subseteq N,(v+\alpha w)(S)=v(S)+\alpha w(S)$. A game $v \in \Gamma$ is monotone if $v(S) \leq v(T)$ for each $S \subseteq T$. For each $v \in \Gamma$, the dual game [15] of $v$ is the game $v^{D} \in \Gamma$ such that, for each $S \subseteq N, v^{D}(S)=v(N)-v(N \backslash S)$.

A sharing rule on $\Gamma$ is a function $\psi$ which associates to each game $v \in \Gamma$ a vector $\psi(v) \in \mathbb{R}^{N}$ describing the payoffs that the players receive for participating in $v$. The following sharing rules 
are well-known. The Shapley value [23] is the sharing rule $S h$ such that, for each $v \in \Gamma$ and each $i \in N$,

$$
S h_{i}(v)=\sum_{S \subseteq N: S \ni i} \frac{(s-1) !(n-s) !}{n !}[v(S)-v(S \backslash\{i\})],
$$

Let $\omega \in \mathbb{R}_{++}^{N}$ be a positive weight vector on $N$. The positively weighted Shapley value associated with $\omega[15]$ is the Sharing rule $S h^{\omega}$ such that, for each $v \in \Gamma$ and each $i \in N$,

$$
S h_{i}^{\omega}(v)=\sum_{S \subseteq N: S \ni i} \frac{\omega_{i}}{\sum_{j \in S} \omega_{j}} \Delta_{v}(S) .
$$

The Shapley value is the positively weighted Shapley value such that $\omega_{i}=\omega_{j}$ for each $i, j \in N$.

The Solidarity value [21] is the sharing rule $S o l$ such that, for each $v \in \Gamma$ and each $i \in N$,

$$
\operatorname{Sol}_{i}(v)=\sum_{S \subseteq N: S \ni i} \frac{(s-1) !(n-s) !}{n !} A^{v}(S) .
$$

The Equal Division value is the sharing rule $E D$ such that, for each $v \in \Gamma$ and each $i \in N$,

$$
E D_{i}(v)=\frac{v(N)}{n} \text {. }
$$

The Equal Surplus Division [or the Center of the imputation set in 10] is the sharing rule ESD such that, for each $v \in \Gamma$ and each $i \in N$,

$$
E S D_{i}(v)=v(\{i\})+\frac{1}{n}\left[v(N)-\sum_{j \in N} v(\{j\})\right] .
$$

\section{Equal treatment of necessary and equal players}

We introduce below the axiom of equal treatment of necessary players. This axiom requires that all players necessary to produce worth shall receive the same payoff.

Equal treatment of necessary players. For each game $v \in \Gamma$ and each player $i, j \in N$ who are necessary in $v$, it holds that $\psi_{i}(v)=\psi_{j}(v)$.

This axiom is proposed as a relaxation of two widely-used axioms: equal treatment of equals and symmetry.

Equal treatment of equals. For each game $v \in \Gamma$ and each player $i, j \in N$ who are equal in $v \in \Gamma$, it holds that $\psi_{i}(v)=\psi_{j}(v)$.

Symmetry. For each permutation $\pi \in \Pi$, each game $v \in \Gamma$ and each $i \in N$, it holds that $\psi_{\pi(i)}(\pi v)=\psi_{i}(v)$.

Equal treatment of equals is weaker than symmetry: any sharing rule satisfying symmetry also satisfies equal treatment of equals, while the converse is not true. Below, we also prove that equal treatment of necessary players is weaker than equal treatment of equals (and in turn than symmetry). 
Proposition 1 Equal treatment of equals implies equal treatment of necessary players.

Proof. Consider any game $v \in \Gamma$ such that two players $i, j \in N$ are necessary in $v$. This means that $v(S)=0$ for all $S \subseteq N$ such that $|S \cap\{i, j\}|<2$. Hence, $v(T \cup\{i\})=v(T \cup\{j\})=0$ whenever $T \subseteq N \backslash\{i, j\}$, meaning that players $i$ and $j$ are equal in $v$. Therefore, equal treatment of equals implies that $\psi_{i}(v)=\psi_{j}(v)$.

Next, from any vector of positive weights $\omega \in \mathbb{R}_{++}^{N}$, construct the game $v_{\omega} \in \Gamma$ such that

$$
v_{\omega}(S)= \begin{cases}\omega_{i} v(\{i\}) & \text { if } S=\{i\}, i \in N \\ v(S) & \text { if } s \geq 2\end{cases}
$$

Now, from any sharing rule $f$ on $\Gamma$ and any positive weight vector $\omega$, construct the sharing rule $\psi^{f, \omega}$ on $\Gamma$ such that, for each game $v \in \Gamma, \psi^{f, \omega}=f\left(v_{\omega}\right)$.

Proposition 2 Equal treatment of necessary players does not imply equal treatment of equals.

Proof. Consider any sharing rule $f$ on $\Gamma$ and any positive weight vector $\omega$. We proceed in two steps. Firstly, we show that if $f$ satisfies equal treatment of equals, then $\psi^{f, \omega}$ satisfies equal treatment of necessary players. Pick any game $v$ in which two players $i, j \in N$ are necessary. Since $v(S)=0$ for any $S \subseteq N \backslash\{i\}$ and any $S \subseteq N \backslash\{j\}$, it holds that $v(\{k\})=0$ for all $k \in N$. This implies that $v_{\omega}=v$. As a consequence, if $f$ satisfies equal treatment of equals, then $\psi^{f, \omega}$ satisfies the equal treatment of necessary players by Proposition 1.

Secondly, we specify $f$ in order to prove that $\psi^{f, \omega}$ violates equal treatment of equals. For this, set $f=E S D$ and suppose that not all coordinates of $\omega$ are equal. Pick any two players $i, j \in N$ such that $\omega_{i} \neq \omega_{j}$ and consider any game $v$ in which $i$ and $j$ are equal. Assume further that their singleton worths are not null. Then, it is clear that $\psi_{i}^{E S D, \omega}(v)-\psi_{j}^{E S D, \omega}(v)=\omega_{i} v(\{i\})-\omega_{j} v(\{j\}) \neq 0$ since $v(\{i\})=v(\{j\})$ for two equal players. Finally, note that this second part can be proved by setting $f=S h$ or $f=S o l$ instead of $f=E S D$, but not with $f=E D$ since the Equal Division value is not sensitive to the worths of singletons.

At this stage, equal treatment of necessary players may seem very close to equal treatment of equals. Hence, it is natural to ask whether it is possible that the combination of equal treatment of necessary players and some other axioms implies equal treatment of equals. In the next results, we provide both negative and positive answers.

A popular class of sharing rules is the class of sharing rules satisfying linearity, efficiency and equal treatment of equals. In this note, for simplicity, we always invoke the axiom of linearity even when it can be weakened into the additivity axiom.

Linearity. For each games $v, w \in \Gamma$ and each real number $\alpha \in \mathbb{R}$, it holds that $\psi(v+\alpha w)=$ $\psi(v)+\alpha \psi(w)$.

Efficiency. For each game $v \in \Gamma$, it holds $\sum_{i \in N} \psi_{i}(v)=v(N)$.

As an example, [22] provide a formulation of any sharing rule satisfying these three axioms. [16] introduce the so-called class of procedural values introduced as a relevant subclass of all sharing 
rules satisfying linearity, efficiency and equal treatment of equals. A Procedural value is the average of contribution vectors associated with all permutations of the player set, where, for each permutation and each player, a procedure specifies how the marginal contribution of this player is shared among herself and all her predecessors in the permutation. Formally, a procedure $l$ is a collection of nonnegative coefficients $\left(\left(l_{p, q}\right)_{q=1}^{p}\right)_{p=1}^{n}$ such that for each $p \in\{1, \ldots, n\}, \sum_{q=1}^{p} l_{p, q}=1$. The coefficient $l_{p, q}$ specifies the share of player at position $q \leq p$ in the marginal contribution of player at position $p$ in the permutation. Obviously, $l_{11}=1$. For each permutation $\pi \in \Pi$, and each $v \in \Gamma$, the procedure $l$ generates a contribution vector $r^{\pi, l}(v)$ defined, for each $i \in N$, as

$$
r_{i}^{\pi, l}(v)=\sum_{j \in\left(N \backslash P_{i}^{\pi}\right) \cup i} l_{\pi(j), \pi(i)}\left(v\left(P_{j}^{\pi}\right)-v\left(P_{j}^{\pi} \backslash j\right)\right) .
$$

The Procedural value associated with procedure $l$ is the sharing rule $P V^{l}$ such that, for each $v \in \Gamma$ and each $i \in N$,

$$
P V_{i}^{l}(v)=\frac{1}{n !} \sum_{\pi \in \Pi_{N}} r_{i}^{\sigma, l}(v)
$$

The class of procedural value is a strict subset of all sharing rules satisfy the axioms of linearity, efficiency and equal treatment of equals: the Shapley value, the Equal Division value and the Solidarity value are procedural values but not the Equal Surplus Division value. [16] characterizes the class of procedural values by these three axioms together with the axioms of monotonicity [also known as positivity in 15] and coalitional monotonicity.

Monotonicity. For each monotone game $v \in \Gamma$ and each $i \in N$, it holds that $\psi_{i}(v) \geq 0$.

Coalitional monotonicity. For each games $v, w \in \Gamma$ such that $v(T)>w(T)$ and $v(S)=w(S)$ for each $S \neq T$, and each $i \in T$, it holds that $\psi_{i}(v) \geq \psi_{i}(w)$.

Even in the presence of linearity, efficiency, monotonicity and coalitional monotonicity, equal treatment of necessary players does not imply equal treatment of equals. In other words, equal treatment of necessary players is not a substitute for equal treatment of equals in the characterization of the class of procedural values by [16].

Proposition 3 The combination of linearity, efficiency, monotonicity, coalitional monotonicity and equal treatment of necessary players does not imply equal treatment of equals.

Proof. Consider the sharing rule $\psi^{S h, \omega}$ as constructed before in Proposition 2 by setting $f=S h$ and $\omega$ such that $\left.\omega_{i} \in\right] 0,1\left[\right.$ for each $i \in N$. Since $n \geq 2, v_{\omega}(N)=v(N)$. Thus, if a sharing rule $f$ satisfies efficiency, then $\psi^{f, \omega}$ clearly inherits efficiency from $f$. Similarly, the weight vector being exogenous (i.e. the weights do not depend on the characteristic function), if $f$ is linear, then $\psi^{f, \omega}$ is linear too. Combining these two remarks with the first part of the proof of Proposition 2, we obtain that for any $f$ satisfying linearity, efficiency and equal treatment of equals, $\psi^{f, \omega}$ satisfies linearity, efficiency and equal treatment of necessary players. Hence, $\psi^{S h, \omega}$ satisfies linearity, efficiency, equal treatment of necessary players but not equal treatment of equals by Proposition 2. So, it only remains to show that $\psi^{S h, \omega}$ satisfies monotonicity and coalitional monotonicity. Firstly, consider any monotone game $v$. Since $\left.\omega_{i} \in\right] 0,1\left[\right.$ for each $i \in N$, we have $\left.v_{\omega}(\{i\}) \in\right] 0, v(\{i\})[$ for each $i \in N$ and $v_{\omega}(S)=v(S)$ for each $S$ such that $s \neq 1$. Therefore, for each $i \in N$ and each $S \subseteq N$ 
with $i \in S, 0=v(\emptyset) \leq v(\{i\}) \leq v(S)$ implies $0=v_{\omega}(\emptyset) \leq v_{\omega}(\{i\})<v_{\omega}(S)$. This implies that $v_{\omega}$ is monotone too. As a consequence, since $S h$ satisfies monotonicity, $\psi^{S h, \omega}$ satisfies monotonicity as well. Regarding coalitional monotonicity, pick two games $v, w \in \Gamma$ such that $v(T)>w(T)$ and $v(S)=w(S)$ for each $S \neq T$. Since the coordinates of $\omega$ are positive, it holds that $v_{\omega}(T)>w_{\omega}(T)$ and $v_{\omega}(S)=w_{\omega}(S)$ for each $S \neq T$ as well. Hence $\psi^{S h, \omega}$ inherits coalitional monotonicity from Sh.

Proposition 3 means that $\psi^{S h, \omega}$ is not a procedural value. As a corollary, we get that class of sharing rules satisfying linearity, efficiency and equal treatment of necessary players is strictly larger than the class of sharing rules satisfying linearity, efficiency and equal treatment of equals. Below, we temper this negative result by considering the following axiom.

Self-duality. For each game $v \in \Gamma$, it holds that $\psi(v)=\psi\left(v^{D}\right)$.

The Shapley value and the Equal Division value satisfies self-duality, contrary to the Equal Surplus Division value and the Solidarity value. [16] characterizes the procedural values that satisfy self-duality. This axiom is also invoked in [12] and [2].

Proposition 4 The combination of linearity, equal treatment of necessary players and self duality implies equal treatment of equals.

Proof. Consider any sharing rule $\psi$ on $\Gamma$ that satisfies linearity, equal treatment of necessary players and self-duality. For each $S \subseteq N, S \notin\{\emptyset, N\}$ and each $c \in \mathbb{R}$ and each $i \in N$, [2, Lemma 1 (b)] prove that linearity and self-duality implies that

$$
\psi_{i}\left(c\left(\delta_{S}+\delta_{N \backslash S}\right)\right)=0 .
$$

Now, consider any game $v \in \Gamma$ in which two players $i$ and $j$ are equal. Consider any ordering $\left(S^{k}\right)_{k=1}^{2^{n-1}-1}$ of all nonempty coalitions not containing player $i$. Set $v^{0}=v$ and define the sequence of games $\left(v^{k}\right)_{k=0}^{2^{n-1}-1}$ such that, for each $k=1, \ldots, 2^{n-1}-1$,

$$
v^{k}=v^{k-1}-v^{k-1}\left(S^{k}\right)\left(\delta_{S^{k}}+\delta_{N \backslash S^{k}}\right) .
$$

For simplicity, denote by $w$ the final game $v^{2^{n-1}-1}$. By construction, we have

$$
w(S)= \begin{cases}0 & \text { if } S \subseteq N \backslash\{i\} \\ v(S)-v(N \backslash S) & \text { if } i \in S\end{cases}
$$

This implies that $i$ is necessary in $w$. Now, pick any $S \subseteq N \backslash\{j\}$. There are two cases. If $S \subseteq N \backslash\{i\}$, then (3) implies that $w(S)=0$. If $i \in S$, we can write that

$$
w(S)=v(S)-v(N \backslash S)=v((S \backslash\{i\}) \cup\{j\})-v((N \backslash S) \backslash\{j\}) \cup\{i\})=w((S \backslash\{i\}) \cup\{j\})=0
$$

where the first, third and fourth equalities comes from (3) and the second equality holds since $i$ and $j$ are equal in $v$. Combining the two cases, we conclude that $j$ is necessary in $w$ as well. Applying equal treatment of necessary players in $w$ and $2^{n-1}-1$ times the invariance in (2) to consecutive games $v^{k}$ and $v^{k-1}, k=1, \ldots, 2^{n-1}-1$, we get that $\psi_{i}(v)=\psi_{i}(w)=\psi_{j}(w)=\psi_{j}(v)$, proving that $\psi$ satisfies equal treatment of equals. 
In the rest of this section, we show that equal treatment of necessary players can successfully replace equal treatment of equals in numerous characterizations of well-known sharing rules. Some of these characterizations single out a unique sharing rule among the class of sharing rules satisfying linearity, efficiency and equal treatment of equals by invoking an extra axiom that specifies the type of player who receives a null payoff. Furthermore, in most of the proofs of these characterizations, equal treatment of equals is applied to pairs of equal players that are also necessary. Therefore, replacing equal treatment of equals by equal treatment of necessary players can be done by using proofs that are identical to their original counterparts. We omit such immediate proofs (for Propositions 5, 6 (i) and 7). It should also be clear that the logical independence of the axioms in our characterizations follows from that in their original counterparts.

[24] provides the modern version of the classical axiomatization of the Shapley value by linearity, efficiency, equal treatment of equals and the following axiom.

Null player axiom. For each game $v \in \Gamma$ and each player $i \in N$ who is null in $v$, it holds that $\psi_{i}(v)=0$.

Another well-known characterization of the Shapley value is proposed by [31] who invokes the axiom of strong monotonicity in combination with efficiency and equal treatment of equals.

Strong monotonicity. For each games $v, w \in \Gamma$ and each player $i \in N$ such that $v(S \cup\{i\})-$ $v(S) \geq w(S \cup\{i\})-w(S)$ for each $S \subseteq N \backslash\{i\}$, it holds that $\psi_{i}(v) \geq \psi_{i}(w)$.

The aforementioned two characterizations still hold if we swap equal treatment of equals for equal treatment of necessary players.

Proposition 5 The Shapley value is the unique sharing rule on $\Gamma$ that satisfies efficiency, equal treatment of necessary players and either (i) linearity and the null player axiom or (ii) strong monotonicity.

Two characterizations of the Equal Division value provided by [26] can be revisited. The first one invokes efficiency, equal treatment of equals (named symmetry in that article), linearity and the following nullifying player axiom.

Nullifying player axiom. For each game $v \in \Gamma$ and each player $i \in N$ who is nullifying in $v$, it holds that $\psi_{i}(v)=0$.

The second characterization combines efficiency with strong coalitional monotonicity and weak equal treatment of equals.

Strong coalitional monotonicity. For each pair of games $v, w \in \Gamma$ and each player $i \in N$ such that, for each $S \subseteq N$ with $i \in S, v(S) \geq w(S)$, it holds that $\psi_{i}(v) \geq \psi_{i}(w)$.

Weak equal treatment of equals. For each game $v \in \Gamma$ such that all players are equals in $v$, there is $c \in \mathbb{R}$ such that $\psi_{i}(v)=c$ for each $i \in N$. 
Once again, these results are robust to a replacement of equal treatment of equals by equal treatment of necessary players. In the second one, equal treatment of necessary players can be replaced by the following axiom.

Weak equal treatment of necessary players. For each game $v \in \Gamma$ such that all players are necessary in $v$, there is $c \in \mathbb{R}$ such that $\psi_{i}(v)=c$ for each $i \in N$.

This axiom can be shown to be weaker than the equal treatment of necessary players using a similar reasoning as in Propositions 1 and 2.

Proposition 6 The Equal Division value is the unique sharing rule on $\Gamma$ that satisfies efficiency and either (i) equal treatment of necessary players linearity and the nullifying player axiom or (ii) weak equal treatment of necessary players and strong coalitional monotonicity.

Proof. Only the proof of part (ii) needs an adaptation compared to its counterpart in [26]. We already know that $E D$ satisfies the three axioms. For the uniqueness part, let us divide the set of games $\Gamma$ into two subsets: the set of non-negative games $\Gamma_{+}=\{v \in \Gamma: v(S) \geq 0, \forall S \subseteq N\}$ and the complementary set $\Gamma_{-}=\{v \in \Gamma: \exists S \subseteq N$ with $v(S)<0\}$.

For any game $v \in \Gamma_{+}$, let us consider a game $w_{1} \in \Gamma$ such that $w_{1}(S)=0$ for all $S \subsetneq N$ and $w_{1}(N)=v(N)$. By efficiency and the axiom of weak equal treatment of necessary players, we have $\psi_{i}\left(w_{1}\right)=v(N) / n$. Since $v(S) \geq w_{1}(S)$ for any $S \subseteq N$, strong coalitional monotonicity implies, for each $i \in N$, that

$$
\psi_{i}(v) \geq \psi_{i}\left(w_{1}\right)=\frac{v(N)}{n} .
$$

Using efficiency, we conclude that $\psi_{i}(v)=E D_{i}(v)$ for each $i \in N$.

For any game $v \in \Gamma_{-}$, let us consider a game $w_{1} \in \Gamma$ defined as before and a game $w_{2} \in \Gamma$ defined as

$$
w_{2}(S)= \begin{cases}v(S) & \text { if } v(S) \geq 0 \text { or } S=N, \\ 0 & \text { if } v(S)<0 \text { and } S \neq N,\end{cases}
$$

for each $S \subseteq N$. We have $w_{2}(S) \geq w_{1}(S)$ for all $S \subseteq N$. Strong coalitional monotonicity and weak equal treatment of necessary players then imply that $\psi_{i}\left(w_{2}\right) \geq \psi_{i}\left(w_{1}\right)=v(N) / n$ for each $i \in N$. By efficiency, we get that $\psi_{i}\left(w_{2}\right)=v(N) / n$ for each $i \in N$. It also holds that $w_{2}(S) \geq v(S)$ for all $S \subseteq N$. Again, strong coalitional monotonicity implies $v(N) / n=\psi_{i}\left(w_{2}\right) \geq \psi_{i}(v)$ for each $i \in N$ and efficiency therefore yields that $\psi_{i}(v)=v(N) / n=E D_{i}(v)$ for each $i \in N$.

Finally, [21] offer a characterization of the Solidarity value similar to that of the Shapley value in [24] by replacing the null player axiom by the following axiom in which $A$-null players must get zero payoffs.

$A$-null player axiom. For each game $v \in \Gamma$ and each player $i \in N$ who is $A$-null in $v$, it holds that $\psi_{i}(v)=0$.

A similar characterization is possible by substituting equal treatment of equals for equal treatment of necessary players.

Proposition 7 The Solidarity value is the unique sharing rule on $\Gamma$ that satisfies linearity, the $A$-null player axiom, efficiency and equal treatment of necessary players. 


\section{Equal sign for the payoffs of necessary and equal players}

$[5,6]$ introduces the axioms of sign symmetry and weak sign symmetry, which require identical signs for the payoffs of two equal players and two mutually dependent players, respectively. The obvious difference between sign symmetry and equal treatment of equals is that equal players may not receive identical payoff. The Shapley value is characterized by efficiency, sign symmetry and either strong monotonicity [5] or linearity and the null player axiom [6]. Furthermore, [6] characterizes the class of positively weighted Shapley values by efficiency, linearity, the null player axiom and weak sign symmetry defined below. We introduce a weak variant of the sign symmetry and weak sign symmetry which imposes the same requirement but for pairs of necessary players.

Equal sign for necessary players. For each $v \in \Gamma$ and each $i, j \in N$ who are necessary in $v$, it holds that $\operatorname{sign}\left(\psi_{i}(v)\right)=\operatorname{sign}\left(\psi_{i}(v)\right)$, where sign $: \mathbb{R} \rightarrow\{-1,0,1\}$ is the function such that $\operatorname{sign}(x)=1$ if $x>0, \operatorname{sign}(x)=0$ if $x=0$ and $\operatorname{sign}(x)=-1$ if $x<0$.

Note that two mutually dependent players are equal, while the converse does not hold. Furthermore, two necessary players are mutually dependent. The converse implication is not true. To see this, construct the game $v$ such that, for two distinct players $i, j \in N$ and each nonempty coalition $S \subseteq N \backslash\{i, j\}, v(S)>0$ and $v(S \cup\{i\})=v(S)=v(S \cup\{j\})$. Players $i$ and $j$ are mutually dependent but not necessary in $v$. Combining these remarks, we obtain that sign symmetry implies weak sign symmetry, which in turn implies equal sign for necessary players, while the converse implications do not hold. Below, we prove that equal sign for necessary players is a substitute for weak sign symmetry in the characterization of the positively weighted Shapley value in [6].

Proposition 8 A sharing rule on $\Gamma$ satisfies linearity, the null player axiom, efficiency and equal sign for necessary players if and only if it is a positively weighted Shapley value.

It is worth mentioning that a key step in the proofs of $[5,6]$ rely on games in which equal or mutually dependent players may not be necessary players. As a consequence, we cannot mimic these proofs to demonstrate Proposition 8. Instead, we offer a different, but nonetheless elegant, proof.

Proof. It is well-known that any positively weighted Shapley value $S h^{\omega}$ satisfies efficiency, linearity and the null player axiom. Regarding equal sign for necessary players, consider a game $v$ such that two players $i$ and $j$ are necessary in $v$. Since $\Delta_{v}(S)=0$ for each $S \subseteq N$ such that $\{i, j\} \nsubseteq \subseteq$, for each $k \in\{i, j\}$, it holds that

$$
S h_{k}^{\omega}(v)=\sum_{S \subseteq N: S \supseteq\{i, j\}} \frac{\omega_{k}}{\sum_{r \in S} \omega_{r}} \Delta_{v}(S)=\omega_{k} \sum_{S \subseteq N: S \supseteq\{i, j\}} \frac{\Delta_{v}(S)}{\sum_{r \in S} \omega_{r}} .
$$

Hence,

$$
\frac{S h_{i}^{\omega}(v)}{S h_{j}^{\omega}(v)}=\frac{\omega_{i}}{\omega_{j}}>0
$$

which implies that either both $S h_{i}^{\omega}(v)>0$ and $S h_{j}^{\omega}(v)>0$ or both $S h_{i}^{\omega}(v)<0$ and $S h_{j}^{\omega}(v)<0$, proving that $\operatorname{sign}\left(S h_{i}^{\omega}(v)\right)=\operatorname{sign}\left(S h_{i}^{\omega}(v)\right)$.

For the uniqueness part, consider any sharing rule $\psi$ on $\Gamma$ that satisfies the four axioms. By linearity, it is enough to show that $f_{i}\left(u_{S}\right)=S h_{i}^{\omega}\left(u_{S}\right)=\omega_{i} / \sum_{j \in S} \omega_{j}$ for each $S \subseteq N$. By the null 
player axiom and efficiency, this immediately holds for each $S$ with $s=1$. So assume that $s \geq 2$. The null player axiom imposes $\psi_{i}\left(u_{S}\right)=0$ for each $i \in N \backslash S$, so that efficiency yields

$$
\sum_{i \in S} \psi_{i}\left(u_{S}\right)=1
$$

By equal sign for necessary players, we conclude that $\psi_{i}\left(u_{S}\right)>0$ for each $i \in S$. Next, let us prove that for each pair of distinct coalitions $S, T$ and each pair of distinct players $i, j$ such that $\{i, j\} \subseteq S \cap T$, it holds that

$$
\frac{\psi_{i}\left(u_{S}\right)}{\psi_{i}\left(u_{T}\right)}=\frac{\psi_{j}\left(u_{S}\right)}{\psi_{j}\left(u_{T}\right)}
$$

We proceed by contradiction. So, without any loss of generality, assume that

$$
\frac{\psi_{i}\left(u_{S}\right)}{\psi_{i}\left(u_{T}\right)}>\frac{\psi_{j}\left(u_{S}\right)}{\psi_{j}\left(u_{T}\right)}
$$

for some distinct coalitions $S, T$ and some distinct players $i, j$ such that $\{i, j\} \subseteq S \cap T$. We can pick a constant

$$
c \in] \frac{\psi_{j}\left(u_{S}\right)}{\psi_{j}\left(u_{T}\right)}, \frac{\psi_{i}\left(u_{S}\right)}{\psi_{i}\left(u_{T}\right)}[
$$

Then, construct the game $z=u_{S}-c u_{T}$. Since $i$ and $j$ are necessary players in both $u_{S}$ and $u_{T}$, they are necessary players in $z$ too. By linearity and the definition of $c$, we have

$$
\psi_{i}(z)=\psi_{i}\left(u_{S}\right)-c \psi_{i}\left(u_{T}\right)>\psi_{i}\left(u_{S}\right)-\frac{\psi_{i}\left(u_{S}\right)}{\psi_{i}\left(u_{T}\right)} \psi_{i}\left(u_{T}\right)=0
$$

and

$$
\psi_{j}(z)=\psi_{j}\left(u_{S}\right)-c \psi_{j}\left(u_{T}\right)<\psi_{j}\left(u_{S}\right)-\frac{\psi_{j}\left(u_{S}\right)}{\psi_{j}\left(u_{T}\right)} \psi_{j}\left(u_{T}\right)=0,
$$

which implies that $\psi$ violates equal sign for necessary players, a contradiction. Now, set $\omega_{i}=\psi_{i}\left(u_{N}\right)$ for each $i \in N$. For each $S \subsetneq N$ with $s \geq 2$, (5) implies that

$$
\frac{\psi_{i}\left(u_{S}\right)}{\omega_{i}}=\frac{\psi_{j}\left(u_{S}\right)}{\omega_{j}} .
$$

Summing on $j \in S$ and using (4), the previous equality becomes

$$
\psi_{i}\left(u_{S}\right)=\frac{\omega_{i}}{\sum_{j \in S} \omega_{j}}=S h_{i}^{\omega}\left(u_{S}\right)
$$

for each $i \in S$. This completes the proof.

The axioms invoked in Proposition 8 are logically independent:

- The null sharing rule satisfies linearity, the null player axiom and equal sign for necessary players but not efficiency.

- The Equal Division value satisfies linearity, efficiency and equal sign for necessary players but not the null player axiom. 
- The sharing rule $\psi$ which assigns to each game $v \in \Gamma$ and to each $i \in N$ the marginal vector $\psi_{i}(v)=v(\{1, \ldots, i\})-v(\{1, \ldots, i\} \backslash\{i\})$ satisfies linearity, efficiency and the null player axiom but not equal sign for necessary players.

- The sharing rule which coincides with the Shapley value on the class of games with a nonempty set of null players and with the Equal Division value otherwise satisfies the null player axiom, efficiency and equal sign for necessary players but not linearity.

Remark 1. An anonymous reviewer pointed out a sketch of the following alternative proof. It is well-known that linearity and the null player axiom imply marginality [as defined by 31], which imposes that a player obtains the same payoff in two games in her marginal contributions are the same across the two games. For any game $v$ in which two players $i, j \in N$ are mutually dependent we can build a game $w$ such that $w(S)=0$ if $\{i, j\} \nsubseteq S$ and $w(S \cup\{i, j\})=v(S \cup\{i, j\})-v(S \cup\{i\})=$ $v(S \cup\{i, j\})-v(S \cup\{j\})$ for all $S \subseteq N \backslash\{i, j\}$. In $w$, the two players $i$ and $j$ are necessary and their marginal contributions are equal to their marginal contributions in $v$. Therefore, using equal sign for necessary players we obtain $\operatorname{sign}\left(\psi_{i}(w)\right)=\operatorname{sign}\left(\psi_{j}(w)\right)$, using marginality yields $\psi_{i}(w)=\psi_{i}(v)$ and $\psi_{j}(w)=\psi_{j}(v)$ which in turn implies $\operatorname{sign}\left(\psi_{i}(v)\right)=\operatorname{sign}\left(\psi_{j}(v)\right)$. In summary, linearity and null player axiom implies marginality which, together with of equal sign for necessary players, imply weak sign symmetry. From here we can conclude from [6, Theorem 3].

\section{Equal treatment of necessary and equal coalitions}

Another approach investigated by [3] and [13] is based on coalitional variants of equal treatment of equals. Instead of equal players, these articles consider equal coalitions. In this section, we consider necessary coalitions instead of necessary players and we introduce two axioms inspired by those in [3]. For completeness, it should be noted that the axioms invoked in [3] are slightly more general in that they compare players and coalitions with respect to the desirability relation, but they imply equal treatment of equals.

Equal treatment of necessary coalitions. For each game $v \in \Gamma$ and each $S, T \subseteq N$ that are necessary in $v$, it holds that $\sum_{i \in S} \psi_{i}(v)=\sum_{i \in T} \psi_{i}(v)$.

Average equal treatment of necessary coalitions. For each game $v \in \Gamma$ and each $S, T \subseteq N$ that are necessary in $v$, it holds that $\sum_{i \in S} \psi_{i}(v) / s=\sum_{i \in T} \psi_{i}(v) / t$.

Equal treatment of necessary coalitions imposes the same total payoff within each necessary coalition, while average equal treatment of necessary coalitions accounts for the possible differences in size by relying on the average payoffs. Obviously, these axioms reduce to equal treatment of necessary players when $s=t=1$. The results below are similar to those in [3] but with different proofs.

Proposition 9 There is no sharing rule on $\Gamma$ that satisfies efficiency and equal treatment of necessary coalitions.

Proof. Consider the unanimity game $u_{N}$. Since all players are necessary, equal treatment of necessary coalitions and efficiency imply that $\psi_{i}\left(u_{N}\right)=1 / n$ for each $i \in N$. Moreover, for any pair $\{i, j\}$ of distinct players and any $T \subseteq N \backslash\{i, j\}, u_{N}(T)=0$, which means that $\{i, j\}$ is 
a necessary coalition. Applying equal treatment of necessary coalitions to $\{i, j\}$ and $\{j\}$ yields that $\psi_{i}\left(u_{N}\right)+\psi_{j}\left(u_{N}\right)=\psi_{j}\left(u_{N}\right)$, or equivalently that $\psi_{i}\left(u_{N}\right)=0$, a contradiction with the above equality $\psi_{i}\left(u_{N}\right)=1 / n$.

Proposition 10 The Equal Division value is the unique sharing rule on $\Gamma$ that satisfies efficiency, linearity and average equal treatment of necessary coalitions.

Proof. It is easy to check that the Equal Division value satisfies average equal treatment of necessary coalitions (in addition to efficiency and linearity). For the uniqueness part, let $\psi$ be any sharing rule on $\Gamma$ that satisfies the three axioms. By linearity, it is enough to show that $\psi\left(\delta_{S}\right)$ is uniquely determined for each nonempty $S \subseteq N$. Pick any $i \in S$. For each $T \subseteq N \backslash\{i\}, \delta_{S}(T)=0$, which implies that $\{i\}$ is a necessary coalition. Furthermore, $N$ is trivially a necessary coalition. An application of average equal treatment of necessary coalitions to $\{i\}$ and $N$ yields that

$$
\psi_{i}\left(\delta_{S}\right)=\frac{1}{n} \sum_{j \in N} \psi_{j}\left(\delta_{S}\right),
$$

so that efficiency implies $\psi_{i}\left(\delta_{S}\right)=\delta_{S}(N) / n$ for each $i \in S$. For each $j \in N \backslash S$ (if any), each $i \in S$ and each $T \subseteq N \backslash\{i, j\}$, it holds that $\delta_{S}(T)=0$. Thus, $\{i, j\}$ is another necessary coalition. Applying average equal treatment of necessary coalitions to $\{i, j\}$ and $N$ and efficiency yield that

$$
\frac{1}{2}\left(\psi_{i}\left(\delta_{S}\right)+\psi_{j}\left(\delta_{S}\right)\right)=\frac{\delta_{S}(N)}{n},
$$

and since we already found that $\psi_{i}\left(\delta_{S}\right)=\delta_{S}(N) / n$, we conclude that $\psi_{j}\left(\delta_{S}\right)=\delta_{S}(N) / n$ for each $i \in N \backslash S$.

The axioms invoked in Proposition 10 are logically independent:

- The null sharing rule satisfies linearity and average equal treatment of necessary coalitions but not efficiency.

- The Shapley value satisfies efficiency and linearity but not average equal treatment of necessary coalitions.

- The sharing rule which coincides with the Shapley value on the class of games in which $N$ is the unique necessary coalition and with the Equal Division value otherwise satisfies efficiency and average equal treatment of necessary coalitions but not linearity.

Remark 2. Another plausible definition for a necessary coalition, suggested by an anonymous reviewer, is the following: a coalition $S \subseteq N$ is necessary if it holds that $v(T)=0$ for all $T \subseteq N$ such that $S \nsubseteq T$. This definition implies that every $i \in S$ is a necessary player. Therefore, given two necessary coalitions $S$ and $T$, if a sharing rule $\psi$ satisfies the equal treatment of necessary players, then the average payoff in $S$ is equal to the average payoff in $T$. Hence $\psi$ satisfies as well the axiom of average equal treatment of necessary coalitions based on the above alternative definition of a necessary coalition. As a consequence, Proposition 10 does not hold anymore if this alternative definition of a necessary coalition is used. In fact, in addition to the Equal Division value, the Shapley value, the Equal Surplus Division value and the Solidarity value satisfy the associated axiom of average equal treatment of necessary coalitions. At the same time, it can be checked that Proposition 9 remains valid under the alternative definition of a necessary coalition. 


\section{Concluding remarks}

The results presented in section 3 are only a few examples from the wide range of characterizations in which equal treatment of necessary players can replace equal treatment of equals. As a conclusion, we briefly mention other such results. To begin with, [8, point 4 on page 127] already points out that his characterization of the Shapley value by symmetry, the carrier axiom [23] and the so-called difference formula axiom still works when equal treatment of necessary players replaces equal treatment of equals. Similarly, it is immediate to prove that equal treatment of necessary players can replace equal treatment of equals in the third characterization of the Equal Division value provided by [26, Theorem 3.2] by means of efficiency, coalitional standard equivalence and equal treatment of equals. The same substitution holds for the characterization of the consensus value, i.e. the average between the Shapley value and the Equal Surplus Division value, by means of efficiency, equal treatment of equals, the neutral dummy property and linearity in [14]. So far, all these examples operate on a fix player set. Allowing variable player sets, it is straightforward to show that the characterizations of the Equal Surplus Division value in [7] remain valid when equal treatment of necessary players replace equal treatment of equals. These characterizations involve efficiency, equal treatment of equals, strategic equivalence and either population solidarity or population fair-ranking. All these results suggest that a universal demonstration that equal treatment of necessary player can be a substitute for equal treatment of equals may exist. This is left for future work. Finally, [29] has weakened the axiom of balanced contributions [19] by applying it only to pairs of equal players. They called it balanced contributions for symmetric players. In any axiomatization of a sharing rule satisfying symmetry, they prove that replacing symmetry with this weaker axiom results in new axiomatizations of the sharing rule. It remains an open question as whether the same result holds if the principle of balanced contributions is applied to pairs of necessary players only.

\section{Acknowledgement}

This research has benefited from the financial support of IDEXLYON from Université de Lyon (project INDEPTH) within the Programme Investissements d'Avenir (ANR-16-IDEX-0005) and "Mathématiques de la décision pour l'ingénierie physique et sociale" (MODMAD).

\section{References}

[1] Arin, J., Feltkamp, V., 1997. The Nucleolus and Kernel of veto-rich transferable utility games. International Journal of Game Theory 26, 61-73.

[2] Béal, S., Casajus, A., Huettner, F., Rémila, E., Solal, P., 2016. Characterizations of weighted and equal division values. Theory and Decision 80, 649-667.

[3] Béal, S., Rémila, E., Solal, P., 2019. Coalitional desirability and the equal division value. Theory and Decision 86, 95-106.

[4] Casajus, A., 2011. Differential marginality, van den Brink fairness, and the Shapley value. Theory and Decision $71,163-174$.

[5] Casajus, A., 2018. Sign symmetry vs symmetry: Young's characterization of the Shapley value revisited. Economics Letters 169, 59-62.

[6] Casajus, A., 2019. Relaxations of symmetry and the weighted Shapley values. Economics Letters 176, 75-78.

[7] Chun, Y., Park, B., 2012. Population solidarity, population fair-ranking, and the egalitarian value. International Journal of Game Theory 41, 255-270.

[8] de Clippel, G., 2018. Membership separability: A new axiomatization of the Shapley value. Games and Economic Behavior 108, 125-129. 
[9] Dehez, P., Ferey, S., 2013. How to share joint liability: A cooperative game approach. Mathematical Social Sciences $66,44-50$.

[10] Driessen, T. S. H., Funaki, Y., 1991. Coincidence of and collinearity between game theoretic solutions. OR Spektrum 13, 15-30.

[11] González-Arangüena, E., Manuel, C., Owen, G., del Pozo, M., 2017. The within groups and the between groups Myerson values. European Journal of Operational Research 257, 586-600.

[12] Hernandez-Lamoneda, L., Juarez, R., Sanchez-Sanchez, F., 2008. Solutions without dummy axiom for TU cooperative games. Economics Bulletin 3, 1-9.

[13] Hu, X.-F., 2019. Coalitional surplus desirability and the equal surplus division value. Economics Letters 179, $1-4$.

[14] Ju, Y., Borm, P., Ruys, P., 2007. The consensus value: A new solution concept for cooperative games. Social Choice and Welfare 28, 685-703.

[15] Kalai, E., Samet, D., 1987. On weighted Shapley values. International Journal of Game Theory 16, 205-222.

[16] Malawski, M., 2013. "Procedural" values for cooperative games. International Journal of Game Theory 42, 305-324.

[17] Manuel, C., Ortega, E., del Pozo, M., 2020. Marginality and Myerson values, forthcoming in European Journal of Operational Research.

[18] Myerson, R. B., 1977. Graphs and cooperation in games. Mathematics of Operations Research 2, 225-229.

[19] Myerson, R. B., 1980. Conference structures and fair allocation rules. International Journal of Game Theory 9, 169-182.

[20] Navarro, F., 2019. Necessary players, Myerson fairness and the equal treatment of equals. Annals of Operations Research 280, 111-119.

[21] Nowak, A. S., Radzik, T., 1994. A solidarity value for $n$-person transferable utility games. International Journal of Game Theory 23, 43-48.

[22] Ruiz, L. M., Valenciano, F., Zarzuelo, J. M., 1998. The family of least square values for transferable utility games. Games and Economic Behavior 24, 109-130.

[23] Shapley, L. S., 1953. A value for $n$-person games. In: Kuhn, H. W., Tucker, A. W. (Eds.), Contribution to the Theory of Games vol. II, Annals of Mathematics Studies 28. Princeton University Press, Princeton, pp. 307-317.

[24] Shubik, M., 1962. Incentives, decentralized control, the assignment of joint costs and internal pricing. Management Science 8, 325-343.

[25] Sprumont, Y., 1990. Population monotonic allocation schemes for cooperative games with transferable utility. Games and Economic Behavior 2, 378-394.

[26] van den Brink, R., 2007. Null players or nullifying players: the difference between the Shapley value and equal division solutions. Journal of Economic Theory 136, 767-775.

[27] van den Brink, R., Funaki, Y., 2009. Axiomatizations of a class of equal surplus sharing solutions for TU-games. Theory and Decision 67, 303-340.

[28] van den Brink, R., Gilles, R. P., 1996. Axiomatizations of the Conjunctive Permission Value for Games with Permission Structures. Games and Economic Behavior 12, 113-126.

[29] Yokote, K., Kongo, T., 2017. The balanced contributions property for symmetric players. Operations Research Letters 45, 227-231.

[30] Yokote, K., Kongo, T., Funaki, Y., 2018. The balanced contributions property for equal contributors. Games and Economic Behavior 108, 113-124, forthcoming in Games and Economic Behavior.

[31] Young, H. P., 1985. Monotonic solutions of cooperative games. International Journal of Game Theory 14, 65-72. 